\title{
Health and Disease After Assisted Reproductive Technology
}

\author{
Cathy Allen \\ National Maternity Hospital and Merrion Fertility Clinic, Dublin, Ireland
}

\begin{abstract}
Long-term health outcomes after ART have largely focused on offspring health and perinatal parameters. Longer-term health outcomes in female patients remain difficult to fully assess. Hypothetical concerns about the effects of endocrine manipulation on hormone-sensitive conditions, e.g. breast disease, are confounded by variable factors in patients and treatments. Obstetric and perinatal factors endow an additional layer of complexity to the overall analysis and more research is required to appreciate all aspects of ART. Notwithstanding the knowledge gap, clinicians must endeavour to individualise management plans, taking into account the pros and cons of ART in the context of immediate, maternity-related and long-term health risks for their patients.

This review of recent literature examines current ART practice in terms of female health and disease as we strive for best practice in an ever-changing clinical and demographic fertility landscape.
\end{abstract}

Keywords: Maternal Health; Assisted Reproductive Technology; ART; In Vitro Fertilisation; IVF; Pre-eclampsia; Placenta Accrete; Multiple Pregnancy; Donor Egg; Frozen Embryo; Breast Cancer; BRCA; Uterine Cancer; Ovarian Cancer.

\section{INTRODUCTION}

Most assisted reproductive technology (ART) outcome studies and registers have been concerned with offspring outcomes. Particular attention has been given to potential genetic and epigenetic impacts, congenital anomalies and perinatal outcomes. For the most part, the data on ART children are reassuring. The impact of ART on the overall health on female patients through treatment, pregnancy and beyond is complex, and demands multiple considerations. The risks of ART to female health can be broadly divided into short-term, perinatal, and long-term risks, presented in Table 1.

\section{SHORT-TERM COMPLICATIONS AFTER ART}

The short-term/immediate risks to health listed above are in no particular order. Improvements in medication regimens, and better freezing options of gametes and embryos, have resulted in a decline in OHSS risk after ovarian stimulation. The associated risk of thrombosis with OHSS declines in parallel. Together with better ambulatory care options for the management of minor pathologies (e.g. polypectomy), safety in the practical aspects of ART is undoubtedly better now in comparison to previous decades.

However, as demand for in vitro fertilisation (IVF) continues to increase worldwide, and ART services continue to become accessible to a higher number of individuals, more 'high-risk' patients are presenting for fertility care and undergoing ART. Thus, it would seem that the higher safety profile of ART as a treatment is counterbalanced by its application to a higher risk population. Indeed, it might appear that overall measures of health after ART are in a state of equipoise between improved performance indicators of ART success and the subsequent health complications for a population. One example of this can be observed in one large Dublin Obstetric unit where the declining IVF multiple pregnancy rate is in contrast to the increasing maternal age rate (Figs. 1 and 2).

\section{PERINATAL COMPLICATIONS AFTER ART}

In pregnancy-related outcomes, the single biggest determinant of adverse events is the risk of multiple pregnancy. The benefit of elective single embryo transfer (ESET) is now appreciated internationally, but the trend towards reducing multiple pregnancy rate is more readily observed in academic ART clinics, or those that are linked with maternity services.

The risks of abnormal placentation after ART have been shown in previous medical literature (Esh-Broder et al., 2011; Romundstad et al., 2006; Schachter et al., 2002). A review of some more recent publications further emphasises the haemorrhage risk after assisted conception. Luke and colleagues recently published a large study of births in eight American states after subfertility. They stratified haemorrhage risk after IVF using own egg and donor egg, and showed an increased risk of blood transfusion or hysterectomy in pregnancies conceived after own-egg frozen embryo transfer, and donor egg treatments (Luke et al., 2019). In a smaller Italian study of singleton ART pregnancies, Vannucini and colleagues looked at deliveries at two university tertiary care obstetric units. Although this study was matched for age and BMI (but not for parity), the authors found higher post-partum haemorrhage ( $\mathrm{PPH})$ rates in

This is an Open Access article published by World Scientific Publishing Company. It is distributed under the terms of the Creative Commons AttributionNonCommercial-NoDerivatives 4.0 (CC BY-NC-ND) License which permits use, distribution and reproduction, provided that the original work is properly cited, the use is non-commercial and no modifications or adaptations are made.

Received 23 June 2019; Accepted 20 July 2019; Published 20 August 2019

Correspondence should be addressed to: Dr. Cathy Allen, National Maternity Hospital, Holles Street, Dublin 2, Ireland. Email: callen@nmh.ie; drcathyallen@ me.com; callen@merrionfertility.ie 
Table 1. Short-term, perinatal, and long-term risks of ART to female health.

\begin{tabular}{lll}
\hline Short-term & \multicolumn{1}{c}{ Perinatal } & \multicolumn{1}{c}{ Long-term } \\
\hline Ovarian Hyperstimulation Syndrome (OHSS) & Multiple pregnancy & Mental health after success/failure \\
Thromobo-embolic disease & Placentation - previa, accreta, postpartum & Relationships \\
& haemorrhage (PPH) & Family dynamics \\
Surgical complications & Caesarean section & Breast cancer \\
Medical complications & Implantation with suspected scar defects & Uterine cancer \\
Torsion/cysts & Hypertensive disorders & Ovarian cancer \\
Emotional impact of failure/miscarriage & Fetal and neonatal issues; low birth weight; & \\
& large for gestation age; congenital anomalies & \\
\hline
\end{tabular}

Fig. 1. $\mathrm{NMH}^{\star}$ multiple pregnancy rate after IVF 2009-2017.

NMH ART Multiple Pregnancy rate \%

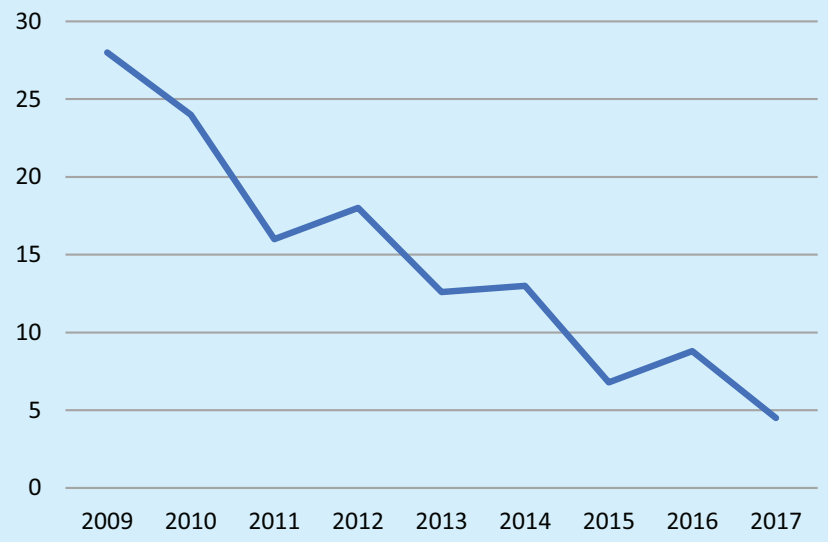

${ }^{*}$ National Maternity Hospital, Dublin.

Fig. 2. $\mathrm{NMH}^{*}$ deliveries of women aged over 40 years, 2002-2018

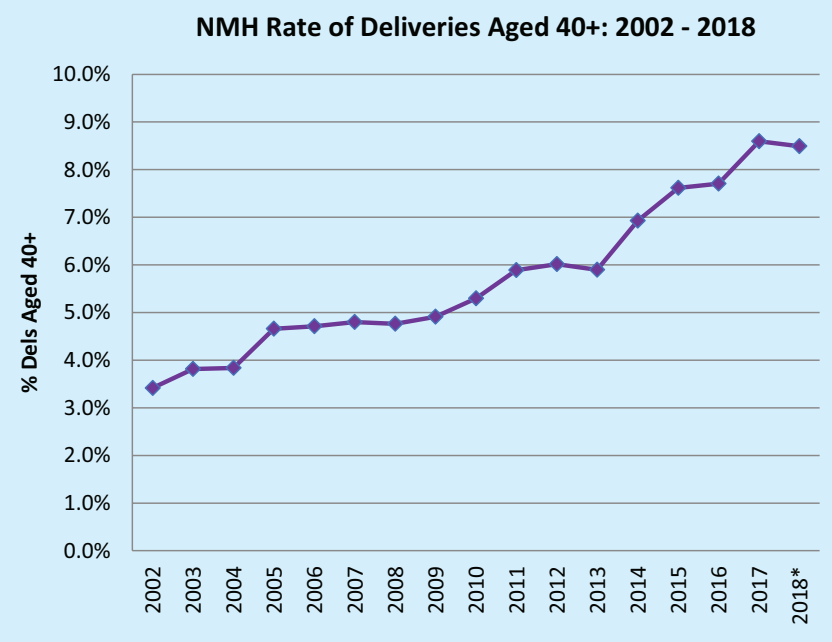

*National Maternity Hospital, Dublin.

the ART pregnancies. They suggest that seemingly uncomplicated pregnancy proceeding to term may require counseling about the risk of placental retention with PPH (Vannuccini et al., 2018).
In recent years the $\mathrm{WHO}$ has expressed concern about the rise in the numbers of caesarean section (CS) births and the potential negative consequences for maternal and infant health (WHO, 2015) An increased CS rate results in an increased proportion of patients with a uterine scar undergoing ART. In the ultrasound assessment of some of these patients, attention may be drawn to the possibility of a scar defect. A growing concern and challenge lies in the transfer of an embryo(s) in the presence of a suspected scar defect, particularly in the context of an increased background risk of abnormal placentation after ART. It is plausible to believe that modern imaging, with its higher resolution, is simply visualising scars more clearly. However, in the arena of ART, where pregnancy complications could be construed as iatrogenic, the further risk of scar ectopics, placenta accrete/percrete are a key concern for maternal and fetal health.

Hypertensive disorders in pregnancy are known to occur more frequently in donor egg conceptions, and thought to result from immune-mediated disorders of trophoblast invasion. Recent studies describe increased relative risks of pregnancy induced hypertension and pre-eclamptic toxaemia in the order of 2.1 to 5.8 fold (Elenis et al., 2015; Ginström Ernstad et al., 2019; Jeve et al., 2016a, 2016b; Le Ray et al., 2019; Nejdet et al., 2016; Okun and Sierra, 2014; Storgaard et al., 2017. My personal obstetric practice is to treat all women with donor egg conceptions with aspirin from 12 to 34 weeks gestation, with the aim of reducing the risk of early onset PET.

Cryopreservation of embryos affords many benefits to patients, including the support of ESET practice and the deferral of embryo transfer in cases at risk of OHSS. The reliability of modern freezing techniques has facilitated a trend towards "freeze-all" with a significant reduction in OHSS. The medical literature has also indicated improvements in perinatal outcomes after frozen embryo transfer compared with fresh, with reduced incidence of antepartum haemorrhage and other complications. Ginström Ernstad and colleagues, studied IVF births in Sweden from 2005 to 2015. They observed more adverse obstetric outcomes after programmed (using hormone replacement) FET cycles, and suggest this may be associated with the absence of a corpus luteum (Ginström Ernstad et al., 2019).

Some follow-up studies have demonstrated increased obstetric and perinatal risks in natural conceptions following subfertility, as well as after ART. This suggests that the sub-fertile state itself, and not necessarily the ART, influences subsequent obstetric health parameters. However, recent papers demonstrate higher risks of severe maternal morbidity in IVF pregnancies even after adjustment for confounders (Le Ray et al., 2019; Okun and Sierra, 2014; Luke, 2017). These risks are higher among women with donor egg conceptions. A large part of the association between IVF and severe maternal morbidity appears to be mediated by multiple pregnancy, again underpinning the importance of measures to optimise the chance of singleton pregnancy with ART. 


\section{LONG-TERM COMPLICATIONS AFTER ART}

Clarification of the long-term health implications of ART requires much more data accumulation; this might seem obvious as we are really only observing the $1^{\text {st }}$ generation of ART humans. But with the exponential rise in ART cycles worldwide, as well as the trend towards treating older and more complex patients, long-term surveillance of data and reappraisal of risk are key in the overall safety considerations of ART.

There is growing concern about a hypothetical link between ART and hormone-sensitive cancers. The ideal way to evaluate cancer risk after IVF would include large randomised trials over a long period of time - perhaps 20 years or more, until the average age at which cancer is diagnosed. However, this is neither ethical nor practical. Observational studies have provided the major research tool in this area, with recognised limitations. Observational studies may lead one to assume that the reported risk measure represents the sole effect of the IVF treatment, but this is not necessarily true. The combined effects of parity, age at first birth, infertility, socioeconomic status and a host of other factors must also be considered.

Breast cancer is a classic model of a hormone-dependent malignancy. As the drugs used for ovarian stimulation in IVF treatment increase the levels of endogenous gonadal hormones, concerns arise as to the theoretical risk of breast cancer development after ART.

A review of the literature demonstrates no clear evidence that ovulation induction or IVF increases the risk of breast cancer. However, there may be a transient increase in the incidence of breast cancer in the first year due to earlier diagnosis (Salhab et al., 2005). Williams and colleagues describe no increased risk of invasive breast cancer but increased risks of in situ breast cancer in women who have had assisted reproduction (Williams et al., 2018). In another study, Van den Belt and colleagues describe a significantly lower risk of breast cancer among women who undergoing seven or more IVF cycles compared with women who underwent one or two (hazard ratio [HR]: 0.55) (van den Belt-Dusebout et al., 2016).

Kessous and colleagues describe an association between IVF treatment and ovarian and uterine cancer in a study of 4000 IVF patients (Kessous et al., 2016). Williams and colleagues showed no increased risk of corpus uteri cancer but increased risks of invasive and borderline ovarian tumours in women who had assisted reproduction (Williams et al., 2018). Results suggest that ovarian tumour risks could be due to patient characteristics, rather than assisted reproduction itself, although both surveillance bias and the effect of treatment are also possibilities. In general, the possible increased risk for late onset cancer due to gene dysregulation for tumour suppression requires more long-term follow-up before the true risk can be determined, and ongoing monitoring of this population is essential.

In addition to the challenge of elucidating cancer risk after standard ART, further complexity surrounds the risk of cancer development in women undergoing ART because they have developed, or are at increased risk of developing cancer, and use ART to preserve fertility. Shapira and colleagues, and Derk-Smeets and colleagues, have found no increase in breast cancer risk in BRCA mutation carriers but such cases demand individualised MDT planning (Derks-Smeets et al., 2018; Shapira et al., 2015).

The emotional impact on individuals undergoing ART is undoubtedly intertwined with the baseline effects of involuntary childlessness. Depression, obsessive compulsive behavior, somatisation and vulnerability have been found to be overrepresented in women who underwent IVF treatment, and observed in both successful the unsuccessful patients with more phobia and depression in the latter (Vikström et al., 2015). Metrics to subdivide the specific contribution of ART and the psychological burden it incurs are lacking, but plentiful personal accounts are available through various media platforms. The perceived stigma of infertility and IVF may gradually diminished by 'normalisation' of the issue by celebrity figures, eg Michelle Obama (Obama, 2018). Notwithstanding the anecdotal nature of many reports, subfertility, its treatment and outcomes undoubtedly yield a significant effect on psychological health, and potentially more morbidity than appreciated. The widening impact on family dynamics and geneology of gamete and embryo donation have yet to be fully described.

Finally, it is important to give equal consideration to the health risks of IVF and the risks of progression of pre-existing disease and infertility conditions. The potentially beneficial effects of a pregnancy on endometriosis, some hormone-sensitive cancers, and mental health should be taken into the equation.

\section{CONCLUSION}

Overall, in the application of ART, the importance of comprehensively appraising the pre- and post-conception health of mother and baby i.e., "joined-up thinking" not only for the ART clinician, but for wider considerations in health-care resourcing of Reproductive Medicine cannot be overstated. As in many aspects of IVF, scientific evidence is not abundant. In my opinion, the risk of straightforward (no addons), appropriately indicated ART outweighs the risks of continued involuntary childlessness. The wisdom of course, is knowing when to stop.

\section{REFERENCES}

Derks-Smeets IAP, Schrijver LH, de Die-Smulders CEM, Tjan-Heijnen VCG, van Golde RJT, Smits LJ, Caanen B, van Asperen CJ, Ausems M, Collée M, van Engelen K, Kets CM, van der Kolk L, Oosterwijk JC, van Os TAM, HEBON, Rookus MA, van Leeuwen FE, Gómez García EB. Ovarian stimulation for IVF and risk of primary breast cancer in BRCA1/2mutation carriers. Br J Cancer. 2018;1: 357-63.

Elenis E, Svanberg AS, Lampic C, Skalkidou A, Åkerud H, Sydsjö G. Adverse obstetric outcomes in pregnancies resulting from oocyte donation: a retrospective cohort case study in Sweden. BMC Pregnancy Childbirth. 2015;15:247.

Esh-Broder E, Ariel I, Abas-Bashir N, Bdolah Y, Hochner Celnikier D. Placenta accreta is associated with IVF pregnancies: a retrospective chart review. BJOG. 2011;118:1084-9.

Ginström Ernstad E, Wennerholm UB, Khatibi A, Petzold M, Bergh C. Neonatal and maternal outcome after frozen embryo transfer: increased risks in programmed cycles. Am J Obstet Gynecol. 2019;pii:S0002-9378(19)30487-9.

Jeve YB, Potdar N, Opoku A, Khare M. Donor oocyte conception and pregnancy complications: a systematic review and meta-analysis. BJOG. 2016a;123(9):1471-80.

Jeve YB, Potdar N, Opoku A, Khare M. Three-arm age-matched retrospective cohort study of obstetric outcomes of donor oocyte pregnancies. Int J Gynaecol Obstet. 2016b;133(2):156-8.

Kessous R, Davidson E, Meirovitz M, Sergienko R, Sheiner E. The risk of female malignancies after fertility treatments: a cohort study with 25-year follow-up. J Cancer Res Clin Oncol. 2016;142(1):287-93.

Le Ray C, Pelage L, Seco A, Bouvier-Colle MH, Chantry AA, DeneuxTharaux C, Epimoms StudyGroup. Risk of severe maternal morbidity associated with in vitro fertilisation: a populationbased study. BJOG. 2019;126(8):1033-41. 
Luke B. Pregnancy and birth outcomes in couples with infertility with and without assisted reproductive technology: with an emphasis on US population-based studies. Am J Obstet Gynecol. 2017;217(3):270-81.

Luke B, Brown MB, Wantman E, Baker VL, Doody KJ, Seifer DB, Spector LG. Risk of severe maternal morbidity by maternal fertility status: a US study in 8 states. Am J Obstet Gynecol.2019;220(2):195.e1-195.e12.

Nejdet S, Bergh C, Källén K, Wennerholm UB, Thurin-Kjellberg A. High risks of maternal and perinatal complications in singletons born after oocyte donation. Acta Obstet Gynecol Scand. 2016;95(8):879-86.

Obama M. Becoming. Random Penguin House; 2018.

Okun N, Sierra S. Pregnancy outcomes after assisted human reproduction. J Obstet Gynaecol Can. 2014;36(1):64-83.

Romundstad LB, Romundstad PR, Sunde A, von Düring V, Skjaerven $\mathrm{R}$, Vatten LJ. Increased risk of placenta previa in pregnancies following IVF/ICSI; a comparison of ART and non-ART pregnancies in the same mother. Hum Reprod. 2006;21(9):2353-8.

Salhab M, Al Sarakbi W, Mokbel K. 1995-2005. In vitro fertilization and breast cancer risk: a review. Database of Abstracts of Reviews of Effects (DARE): Quality-assessed Reviews [Internet]. York (UK): Centre for Reviews and Dissemination (UK); 1995-. In vitro fertilization and breast cancer risk: a review. https://www.ncbi. nlm.nih.gov/books/NBK71580

Schachter M, Tovbin Y, Arieli S, Friedler S, Ron-El R, Sherman D. In vitro fertilization is a risk factor for vasa previa. Fertil Steril. 2002;78(3):642-3.

Shapira M, Raanani H, Meirow D. IVF for fertility preservation in breast cancer patients-efficacy and safety issues. J Assist Reprod Genet. 2015;32(8):1171-8.
Storgaard M, Loft A, Bergh C, Wennerholm UB, Söderström-Anttila V, Romundstad LB, Aittomaki K, Oldereid N, Forman J, Pinborg A. Obstetric and neonatal complications in pregnancies conceived after oocyte donation: a systematic review and metaanalysis. BJOG. 2017;124(4):561-72.

van den Belt-Dusebout AW, Spaan M, Lambalk CB, Kortman M, Laven JS, van Santbrink EJ, van der Westerlaken LA, Cohlen BJ, Braat DD, Smeenk JM, Land JA, Goddijn M, van Golde RJ, van Rumste MM, Schats R, Józwiak K, Hauptmann M, Rookus MA, Burger CW, van Leeuwen FE. Ovarian stimulation for in vitro fertilisation and long-term risk of breast cancer. JAMA. 2016; 316:300-12.

Vannuccini S, Ferrata C, Perelli F, Pinzauti S, Severi FM, Reis FM, Petraglia F, Di Tommaso M. Peripartum and postpartum outcomes in uncomplicated term pregnancy following ART: a retrospective cohort study from two Italian obstetric units. Hum Reprod Open. 2018;2018(3):hoy012.

Vikström J, Josefsson A, Bladh M, Sydsjö G. Mental health in women 20-23 years after IVF treatment: a Swedish cross-sectional study. BMJ Open. 2015;5(10):e009426.

WHO reference number: WHO/RHR/15.02. Sexual and Reproductive Health: WHO Statement on Caesarean Section Rates. World Health Organization; April 2015: 8 pp.

Williams CL, Jones ME, Swerdlow AJ, Botting BJ, Davies MC, Jacobs I, Bunch KJ, Murphy MFG, Sutcliffe AG. Risks of ovarian, breast, and corpus uteri cancer in women treated with assisted reproductive technology in Great Britain, 1991-2010: data linkage study including 2.2 million person years of observation. BMJ. 2018;362:k2644. 